\title{
PERHITUNGAN TARIF IMBAL JASA KAFALAH PENSIUN DAN PRAPENSIUNAN BERBASIS WEB PADA PT. PENJAMINAN JAMKRINDO SYARIAH CABANG PALEMBANG
}

\author{
Jemakmun ${ }^{1}$, Arie Nardu ${ }^{2}$ \\ Fakultas Ilmu Komputer, Universitas Bina Darma ${ }^{1,2}$ \\ Jalan Jenderal Ahmad Yani No.12 Palembang \\ Sur-el: jemakmun@mail.binadarma.ac.id ${ }^{1}$, arienardu17@gmail.com²
}

\begin{abstract}
PT Penjaminan Jamkrindo Syariah then abbreviated as PT Jamkrindo Syariah was born from the Sharia Guarantee Division which is a Sharia Business Unit in the Indonesian General Credit Guarantee Company. The problem that arises in the guarantor company is the difficulty in calculating the price of the Kafalah fee when outside the office if it has to do calculations in the office making prospective customers feel the service provided is slow and unable to compete with other competitors, so we need an application that can help sales in calculating the cost of a Kafalah fee if it is outside the office so the calculation process is fast. The application that will be built is a web-based application software and uses the Prototype method.
\end{abstract}

Keywords: PT Penjaminan Jamkrindo Syariah, Prototype Method.

\begin{abstract}
Abstrak : PT Penjaminan Jamkrindo Syariah kemudian disingkat PT Jamkrindo Syariah terlahir dari Divisi Penjaminan Syariah yang merupakan Unit Usaha Syariah di Perusahaan Umum Jaminan Kredit Indonesia. Permasalahan yang timbul dalam perusahaan penjamin adalah sulitnya melakukan perhitungan tarif imbal jasa kafalah pada saat di luar kantor jika harus melakukan perhitungan di kantor membuat calon nasabah merasa pelayanan yang di berikan lambat dan kalah bersaing dengan kompetitor lainnya, sehingga diperlukan sebuah aplikasi yang dapat membantu sales dalam melakukan perhitungan tarif imbal jasa kafalah jika berada di luar kantor sehingga proses perhitungan cepat. Aplikasi yang akan di bangun adalah perangkat lunak aplikasi berbasis web dan menggunakan metode Prototype.
\end{abstract}

Kata kunci: PT Penjaminan Jamkrindo Syariah, Metode Prototype.

\section{PENDAHULUAN}

Teknologi informasi (TI) telah semakin berkembang, teknologi dapat memberi kemudahan dan kecepatan dalam penggunakan untuk kebutuhan tertentu, baik umum maupun khusus. Perkembangan teknologi informasi pada saat ini mempermudah penyebaran informasi keberbagai wilayah, bahkan informasi menyebar dengan cepat sampai ke semua belahan dunia [1]. PT Penjaminan Jamkrindo Syariah kemudian disingkat PT Jamkrindo Syariah terlahir dari Divisi Penjaminan Syariah yang merupakan Unit
Usaha Syariah di Perusahaan Umum Jaminan Kredit Indonesia (PERUM JAMKRINDO). Perum Jamkrindo merupakan Badan Usaha Milik Negara (BUMN) yang bergerak di bidang penjaminan pembiayaan dan merupakan pelopor penjaminan syariah di Indonesia. Perum Jamkrindo memulai kegiatan penjaminan atas pembiayaan lembaga keuangan syariah pada tahun 1997, melalui kerjasama dengan Bank Muamalat yang merupakan Bank Syariah pertama di Indonesia.

Dari tahun ke tahun, bisnis penjaminan syariah semakin berkembang dengan tingkat 
pertumbuhan volume penjaminan kredit PT Penjaminan Jamkrindo Syariah sepanjang januari-agustus 2017 mengalami pertumbuhan hingga $60 \%$, total pembiayaan yang telah dijamin perusahaan adalah senilai $\mathrm{Rp} 7,32$ triliun realisasi tersebut tumbuh sebesar 50\%-60\% dibanding periode yang sama tahun sebelumnya. Di samping itu, Berdasarkan Imbal jasa kafalah (IJK) yang di terima PT Penjaminan jamkrindo syariah adalah sebesar Rp. 292, 74 miliar. Untuk laba tahun berjalan 2018 sebesar Rp. 21,54 miliar atau $116,24 \%$ dari RKAP[2]. Tumbuh pesatnya perusahan semakin banyak pula permintaan pembiayaan yang mengakibatkan sulitnya sales dalam melakukan perhitungan tarif imbal jasa kafalah jika berada di luar kantor karena perhitungan tarif imbal jasa kafalah yang ada hanya tersedia di kantor tidak untuk di luar kantor[3]. Perhitungan di kantor menggunakan Microsoft excel dengan rumus yang sudah di tentukan. Permasalahan yang timbul dalam perusahaan penjamin adalah sulitnya melakukan perhitungan tarif imbal jasa kafalah pada saat di luar kantor jika harus melakukan perhitungan di kantor membuat calon nasabah merasa pelayanan yang di berikan lambat dan kalah bersaing dengan kompetitor lainnya[4]. Sehingga setiap perusahaan diperlukan sebuah aplikasi yang dapat membantu sales dalam melakukan perhitungan tarif imbal jasa kafalah jika berada di luar kantor sehingga proses perhitungan cepat. Aplikasi yang akan di bangun adalah perangkat lunak aplikasi berbasis web dan menggunakan metode Prototype. Prototype adalah suatu metode pengembangan perangkat lunak yang penting untuk Perhitungan Tarif Imbal Jasa Kafalah Pensiun Dan Prapensiunan ... ...(Jemakmun, Arie Nardu) memperhatikan tahapan-tahapannya agar software finalnya dapat diterima oleh penggunanya [5]. Tahapan inilah yang akan menentukan keberhasilan dari sebuah perangkat lunak itu sendiri. Penelitian ini mambahas tentang Perhitungan Tarif Imbal Jasa Kafalah Pensiunan dan Prapensiunan Berbasis Web pada PT. Penjamin Jamkrindo Syariah Cabang Palembang dengan pembatasan masalah pada perhitungan tarif imbal jasa kafalah dan tidak untuk pengajuan pinjaman yang dibangun dengan menggunakan metode Prototype yang berjalan pada platform web.

\section{METODOLOGI PENELITIAN}

\subsection{Metode Penelitian}

Penelitian ini menggunakan metode deskriptif, dimana dengan metode deskriptif ini bisa mendeskripsikan suatu keadaan saja, tetapi bisa juga mendeskripsikan keadaan dalam tahapan-tahapan perkembangannya, penelitian demikian disebut penelitan perkembangan [6]. Dalam penelitian perkembangan ini ada yang bersifat longitudinal atau sepanjang waktu dan ada yang bersifat cross sectional atau dalam potongan waktu.

\subsection{Metode Pengumpulan Data}

Metode pengumpulan data merupakan langkah yang paling strategis, sesuai tujuan utama dari penelitian yaitu mendapatkan data[7]. Metode Pengumpulan Data yang digunakan dalam penelitian ini adalah: a). Wawancara, Dalam metode ini penulis mengumpulkan data 
penelitian dengan bertanya langsung kepada pihak yang bersangkutan yang dapat memberikan informasi yang dibutuhkan. b). Kepustakaan, Mengumpulkan data dengan cara mencari dan mempelajari data-data dari bukubuku ataupun dari referensi lain yang berhubungan dengan penulisan laporan penelitian proposal. Buku yang digunakan penulis sebagai referensi, adapun metode yang digunakan penulis dalam merancang dan mengembangkan dapat dilihat pada daftar pustaka. c). Observasi Metode ini dilakukan dengan cara mengamati langsung keadaan dan kegiatan, guna mendapatkan keterangan yang akurat[8].

\subsection{Metode Pengembangan Sistem}

Metode pengembangan aplikasi yang dipakai dalam penelitian ini yaitu menggunakan Metode Prototype, metode ini merupakan salah satu metode yang banyak digunakan dalam pengembangan perangkat lunak. Metode Prototype sebagai suatu paradigma baru dalam pengembangan sistem informasi manajemen, tidak hanya sekedar suatu evolusi dari metode pengembangan sistem informasi yang sudah ada, tetapi sekaligus merupakan revolusi dalam pengembangan sistem[5].

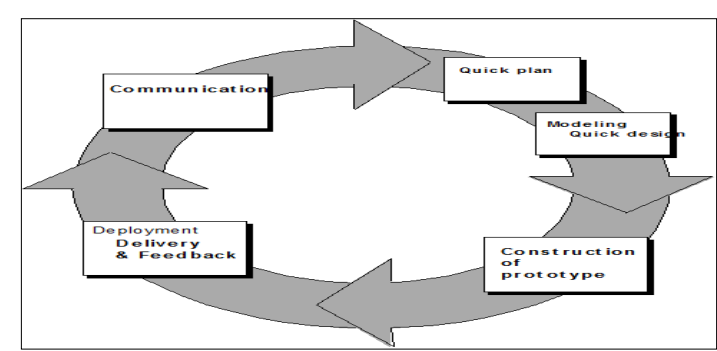

Gambar 1. Metode Prototyping

Metode prototyping sebagai suatu informasi manajemen, tidak hanya sekedar suatu evolusi dari metode pengembangan sistem informasi yang sudah ada, tetapi sekaligus merupakan revolusi dalam pengembangan sistem informasi manajemen. Selain itu, untuk memodelkan sebuah perangkat lunak dibutuhkan beberapa tahapan di dalam proses pengembangannya [9]. Adapun tahapan-tahapan dalam prototyping tersebut adalah sebagai berikut: a). Comunication Pada tahapan ini mendefinisikan permasalahan dan kebutuhan keseluruhan perangkat lunak, mengidentifikasikan semua kebutuhan, dan garis besar sistem yang akan dibuat, b). Quick Plan Rencana cepat dengan membuat perancangan sementara yang berpusat pada penyajian kepada pelanggan, c). Modeling Quick Design, Pemodelan Sistem dalam sistem informasi distribusi ini menggunakan pemodelan sistem menggunakan UML yang terdiri dari usecase diagram, activity diagram dan class diagram, d). Pada tahap ini yang di lakukan oleh peneliti adalah membuat sistem kedalam dalam bahasa pemrograman yang sesuai dalam hal ini menggunakan aplikasi bahasa pemrograman, e). Deployment Delivery and Feedback, Dalam tahapan ini peneliti melakukan pengiriman sistem kepada objek dan menerima feedback dari objek agar sistem yang sudah di bangun oleh peneliti sesuai dengan keinginan objek[10].

paradigma baru dalam pengembangan sistem Perhitungan Tarif Imbal Jasa Kafalah Pensiun Dan Prapensiunan ... ...(Jemakmun, Arie Nardu) 
Selanjutnya hasil penelititan yang dikemukakan adalah membangun aplikasi perhitungan tarif imbal jasa kafalah pensiunan dan prepensiunan berbasis web pada PT. Penjaminan Jamkrindo Syariah Cabang Palembang, maka didapat hasil akhir dari semua kegiatan dan tahapan-tahapan pengembangan sistem yang telah dilakukan merupakan perancangan dari rancangan-rancangan yang telah diuraikan sebelumnya yang terdiri dari desain file, desain input dan desain output. Program yang di gunakan dalam membuat program ini adalah Adobe Dreamweaver CC. Tujuan utama pembuatan program ini adalah untuk membantu tariff imbal jasa kafalah pensiunan dan prepensiunan. Pada tata usaha sistem ini membantu memberikan kemudahan kepada user administrator (pihak pengguna) untuk dapat mempelajari dan mengetahui sistem kerja .

Berikut adalah pembahasan hasil penelitian dimana informasi-informasi yang akan diperlukan saat pembuatan tampilan dan dilakukan proses coding pada halaman login rekayasa perangkat lunak yang menerapkan metode prototype pada system yang akan dibuat.

\subsection{Tampilan Halaman Login}

Halaman login merupakan halaman yang menampilkan form otentikasi bagi admin agar dapat masuk ke sistem. User dapat memasukkan username dan password lalu setelah itu menekan tombol Login. Gambar 2 menunjukkan Halaman login pada Aplikasi yang dibangun.

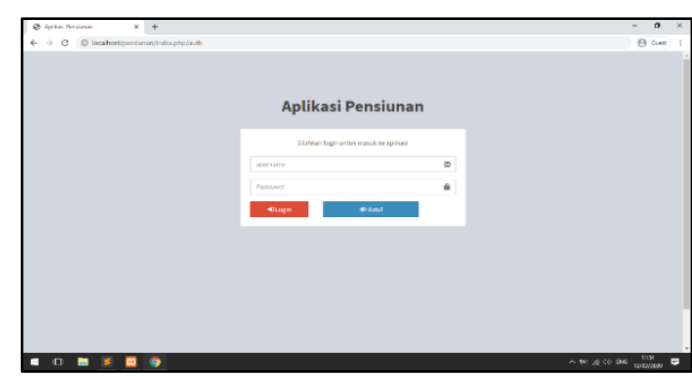

Gambar 2. Halaman Login

\subsection{Tampilan Halaman Beranda}

Halaman beranda adalah halaman yang menampilkan tulisan sambutan selamat datang bagi admin di halaman aplikasi PT. Penjaminan Jamkrindo Syariah Cabang Palembang. Pada halaman ini admin bisa menuju navigasi Beranda, Nasabah, Perhitungan Pensiun, Perhitungan Pra Pensiun, Laporan Pra Pensiun, Laporan Pensiun dan Logout. Gambar 3 merupakan tampilan halaman beranda.

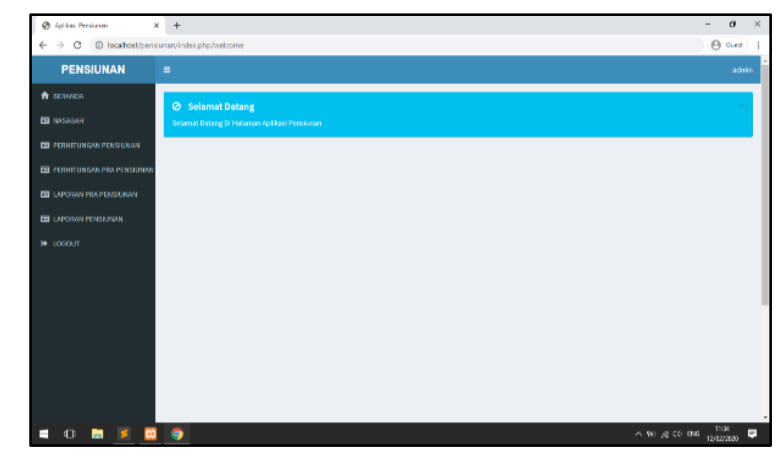

Gambar 3 Tampilan Halaman Beranda

\subsection{Tampilan Halaman Data Nasabah}

Halaman data nasabah adalah halaman yang menampilkan data nasabah yang terdapat pada sistem aplikasi perhitungan tarif imbal jasa kafalah. Data nasabah terdiri dari Nomor, Nama Nasabah, Alamat, Tanggal Lahir, Umur, Jenis Kelamin, dan Pekerjaan. Admin dapat memilih untuk menambah, mengedit maupun menghapus data nasabah yang ada. Gambar 4 merupakan 
tampilan halaman data nasabah.

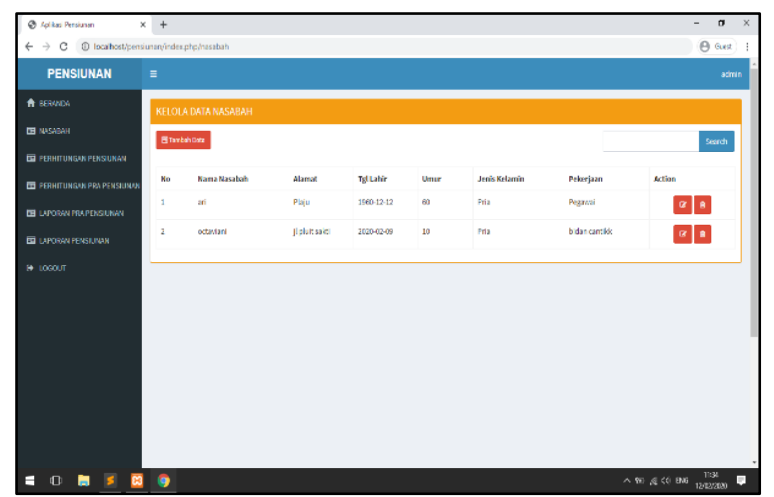

Gambar 4. Tampilan Halaman Data Nasabah

\subsection{Tampilan Halaman Input Data Nasabah}

Halaman input data nasabah adalah halaman yang menampilkan form untuk memasukkan data nasabah yang terdiri dari Nomor, Nama Nasabah, Alamat, Tanggal Lahir, Umur, Jenis Kelamin, dan Pekerjaan. Kemudian, admin dapat menyimpan data dengan menekan tombol Simpan. Gambar 5 merupakan tampilan halaman input data nasabah.

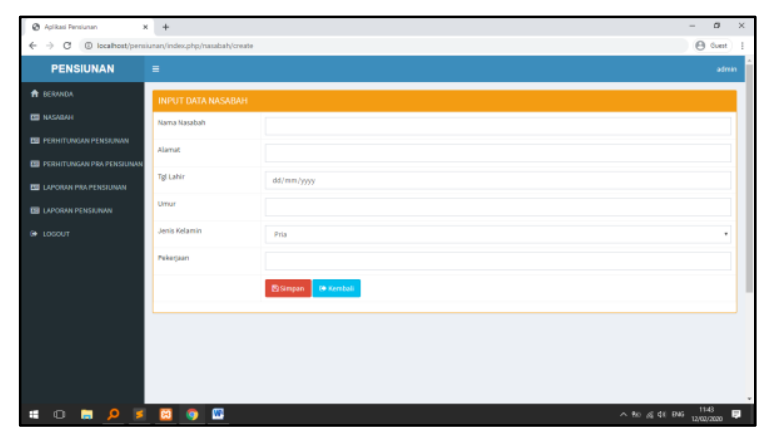

Gambar 5. Tampilan Halaman Input Data

\section{Nasabah}

\subsection{Tampilan Halaman Perhitungan \\ Pensiunan}

Halaman perhitungan pensiunan adalah halaman yang menampilkan data hasil perhitungan pensiunan yang terdiri dari nama nasabah, usia, plafond, teratribusi, plafond ditambah teratribusi, jangka waktu, rate, imbalan jasa kafalah bruto, fee ujrah, dan imbal jasa kafalah nett. Admin juga dapat menambah, menghapus maupun mencetak data yang ada. Gambar 6 merupakan tampilan halaman perhitungan pensiunan.

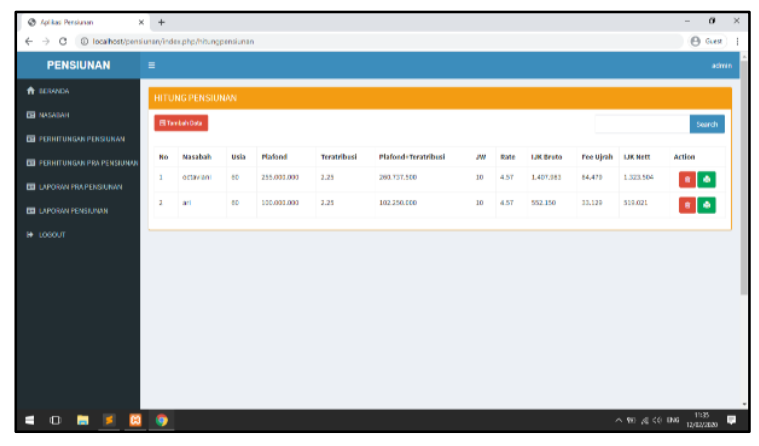

Gambar 6. Tampilan Halaman Perhitungan

\section{Pensiunan}

\subsection{Tampilan Halaman Input Hitungan Pensiunan}

Halaman input hitungan pensiunan adalah halaman yang menampilkan form yang dapat diisi yaitu form nama nasabah, usia, plafond, teratribusi, plafond ditambah teratribusi, jangka waktu, rate, imbalan jasa kafalah bruto, fee ujrah, dan imbal jasa kafalah nett. Setelah itu, Admin dapat menekan tombol Simpan ataupun Kembali. Gambar 7 merupakan tampilan halaman input hitungan pensiunan.

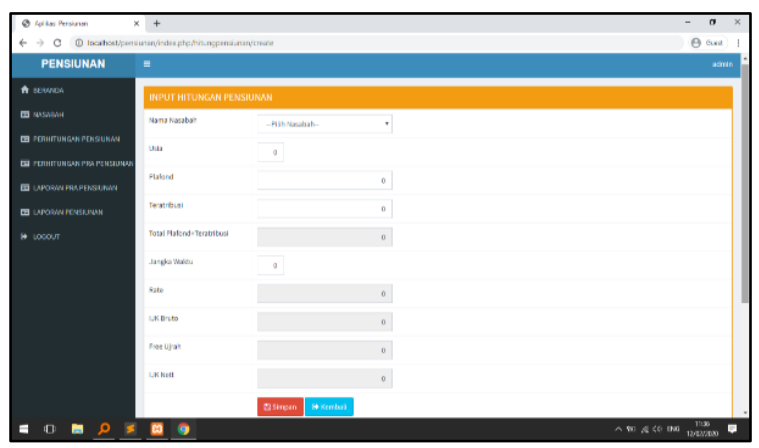

Gambar 7. Tampilan Halaman Input

Hitungan Pensiunan 


\subsection{Tampilan Halaman Cetak Hitungan \\ Pensiun}

Halaman cetak hitungan pensiunan adalah halaman yang menampilkan dokumen yang berisi form nama nasabah, usia, plafond, teratribusi, plafond ditambah teratribusi, jangka waktu, rate, imbalan jasa kafalah bruto, fee ujrah, dan imbal jasa kafalah nett. Dokumen tersebut dapat disimpan maupun dicetak oleh admin. Gambar 8 merupakan tampilan halaman cetak hitungan pensiunan.

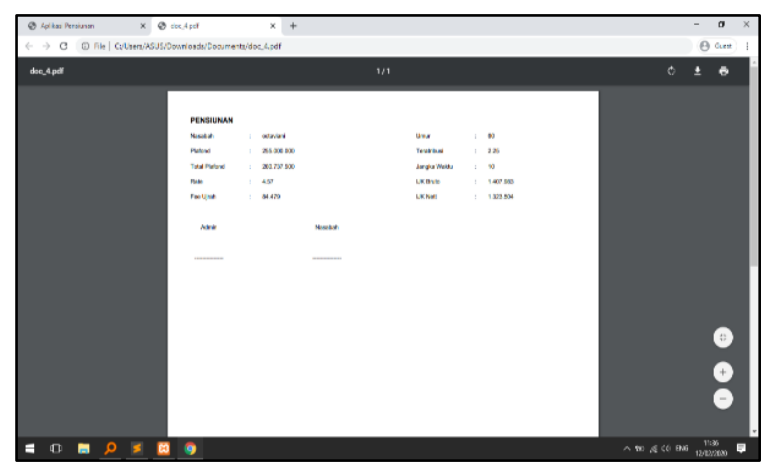

Gambar 8. Tampilan Halaman Cetak Hitungan Pensiun

\subsection{Tampilan Halaman Perhitungan Pra Pensiunan}

Halaman perhitungan pra pensiunan adalah halaman yang menampilkan data hasil perhitungan pensiunan yang terdiri dari nama nasabah, usia, plafond, jangka waktu, rate, dan imbalan jasa kafalah bruto. Admin juga dapat menambah, menghapus maupun mencetak data yang ada. Gambar 9 merupakan tampilan halaman perhitungan pra pensiunan.

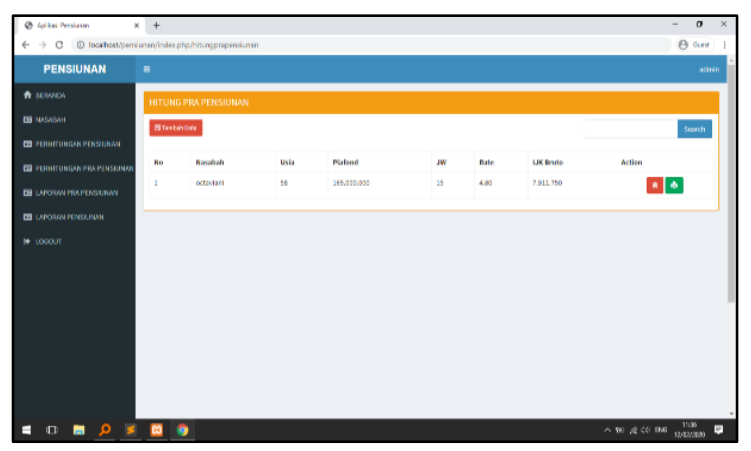

Gambar 9. Tampilan Halaman Perhitungan

\section{Pra Pensiunan}

\subsection{Tampilan Halaman Input Hitungan Pra \\ Pensiunan}

Halaman input hitungan pra pensiunan adalah halaman yang menampilkan form yang dapat diisi yaitu form nama nasabah, usia, plafond, jangka waktu, rate, dan imbalan jasa kafalah bruto. Setelah itu, Admin dapat menekan tombol Simpan ataupun Kembali. Gambar 10 merupakan tampilan halaman input hitungan pra pensiunan.

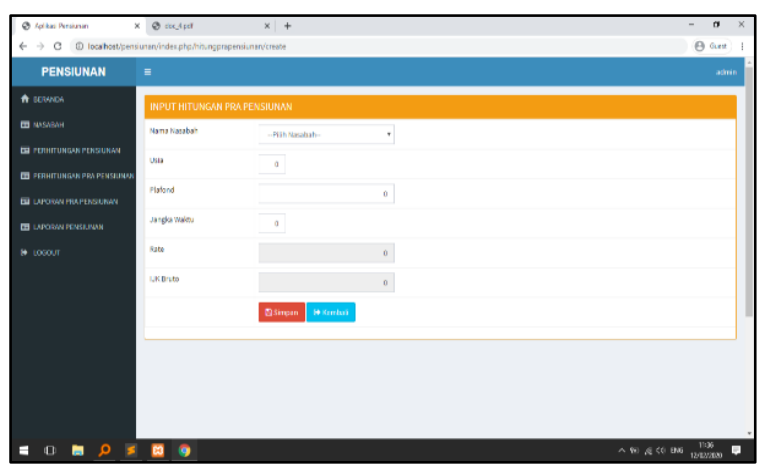

Gambar 10. Tampilan Halaman Input Hitungan Pra Pensiunan

\subsection{Tampilan Halaman Cetak Hitungan Pra Pensiunan}

Halaman cetak hitungan pra pensiunan adalah halaman yang menampilkan dokumen yang berisi form nama nasabah, usia, plafond, jangka waktu, rate, dan imbalan jasa kafalah 
bruto. Dokumen tersebut dapat disimpan maupun dicetak oleh admin. Gambar 11 merupakan tampilan halaman cetak hitungan pra pensiunan.

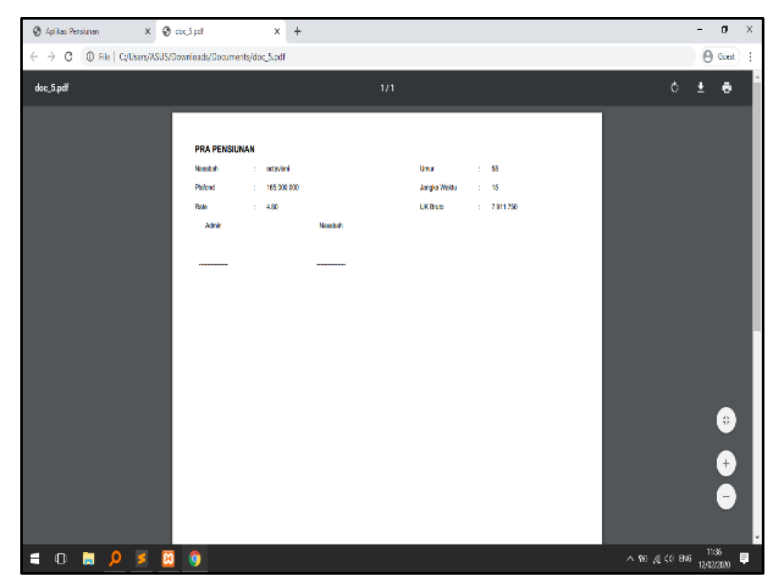

Gambar 11. Tampilan Halaman Cetak

\section{Hitungan Pra Pensiunan}

\subsection{Tampilan Laporan Pra Pensiunan}

Halaman laporan pra pensiunan adalah halaman yang menampilkan dokumen yang berisi form nama nasabah, usia, plafond, jangka waktu, rate, dan imbalan jasa kafalah bruto dari setiap nasabah yang ada. Dokumen tersebut dapat disimpan maupun dicetak oleh admin. Gambar 12 merupakan tampilan halaman laporan pra pensiunan.

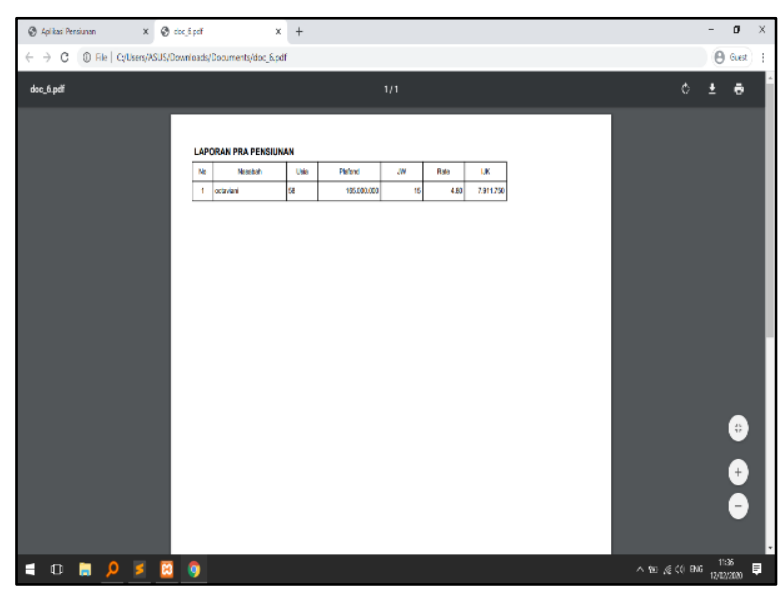

Gambar 12. Tampilan Halaman Laporan Pra Pensiunan

\subsection{Tampilan Halaman Laporan Pensiunan}

Halaman laporan pensiunan adalah halaman yang menampilkan dokumen yang berisi form nama nasabah, usia, plafond, teratribusi, plafond ditambah teratribusi, jangka waktu, rate, imbalan jasa kafalah bruto, fee ujrah, dan imbal jasa kafalah nett dari setiap nasabah yang ada. Dokumen tersebut dapat disimpan maupun dicetak oleh admin. Gambar 13 merupakan tampilan halaman laporan pensiunan.

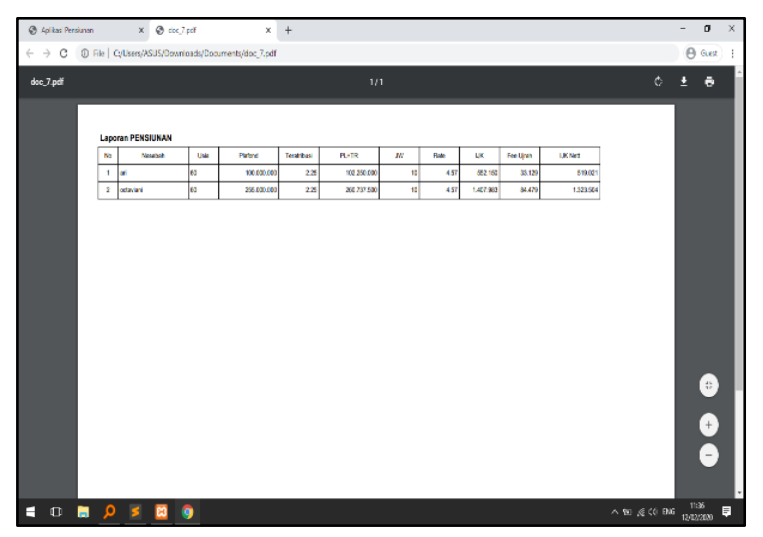

Gambar 13. Tampilan Halaman Laporan Pensiunan

\section{KESIMPULAN}

Berdasarkan hasil penelitian yang telah dilakukan maka kesimpulan yang dapat dikemukakan antara lain:

1. Penelitian ini menerapkan metode prototype pada perangkat lunak yang dapat membantu pihak PT. Penjaminan Jamkrindo Syariah Cabang Palembang dalam menentukan perhitungan tarif imbal jasa kafalah. Diharapkan Aplikasi perhitungan tarif imbal jasa kafalah pensiunan dan prepensiunan 
dapat mengedepankan interface yang berbasis pengalaman pengguna (user experience user interface atau $U X / U I)$ agar dapat menghasilkan tampilan yang lebih menarik.

2. Aplikasi yang dibuat berhasil menjadi perangkat lunak yang efektif untuk membantu karyawan dalam melakukan perhitungan tarif imbal jasa kafalah dimana saja. Diharuskan rutin back-up data pada aplikasi karena dapat menghindari data pada PT. Penjaminan Jamkrindo Syariah Cabang Palembang terjadi kemungkinan hilang.

\section{DAFTAR RUJUKAN}

[1] Murya, Yosep., Pemrograman Android Black Box, Jakarta: Jasakom. 2014.

[2] Tim, " Kafalah Pembiayaan Mikro ", [Online] http://www.jamkrindosyariah.co.id/ ( Accessed: 25-Okt-2019).

[3] Saaty, Thomas L., Pengambilan Keputusan Bagi Para Pemimpin, Proses Hirarki Analitik untuk Pengambilan Keputusan dalam Situasi yang Kompleks. Setiono L, penerjemah; Peniwati K, editor. Jakarta: PT. Pustaka Binaman Pressindo (Terjemahan). 2013.

[4] Saaty, T. L., Decision Making with the Analytic Hierarchy Process . Int. J. Services Sciences, Vol. 1 No. 1, pp. 83-98. 2008.

[5] Pressman, R.S., Software Engineering: a Practitioner's Approach, New York: McGraw-Hill . 2010.

[6] Edvardsson, et al., Pemasaran Jasa Prinsip, Penerapan dan Penelitian; Yogyakarta: Penerbit Andi. 2015.

[7] Sugiyono., Metode Penelitian Pendidikan Pendekatan Kuantitatif, Kualitatif, dan $R \& D$. Bandung: Alfabeta. 2013.

[8] Lupiyoadi, Rambat., Manajemen Pemasaran Jasa. Edisi 3. Jakarta: Salemba Empat. 2014.
[9] Wahana Komputer., Panduan Praktis Pemrograman Borland Delphi 7.0, Edisi Pertama, Semarang: Wahana Komputer. 2013

[10] Haksever et al., Service Management Oprations. USA: Pearson Pretince Hall. 2005. 